taking group had a higher median $(95 \% \mathrm{Cl})$ baPWV (brachial-ankle pulse wave velocity) and median $(95 \% \mathrm{Cl})$ mean pulmonary artery pressure (mPAP) than non-NSAIDs taking group: baPWV $13.72(12.77-15.62)$ vs. 15.29 (13.9317.63) $\mathrm{m} / \mathrm{s}, \mathrm{p}=0.005$; mPAP $26.5(22.8-30.5)$ vs. $30.5(27.3-32.3) \mathrm{mmHg}$, $p=0.011$. But baPWV and mPAP were not significantly different between selective cyclooxygenase-2 inhibitor (22 patients) and nonselective NSAIDs (69patients): baPWV 15.33 (13.98-17.63) vs. 14.83 (13.82-17.39) m/s, $\mathrm{p}=0.191 ; \mathrm{mPAP} 29.0$ (24.5-34.5) vs. $30.0(26.0-33.0) \mathrm{mmHg}, \mathrm{p}=0.960$.

Conclusions: Our study suggests that continuing NSAIDs therapy is associated with increased arterial stiffness in patients with rheumatic diseases, independently noted to increase the incidence of cardiovascular disease.

Disclosure of Interest: None declared

DOI: 10.1136/annrheumdis-2017-eular.2403

\section{AB0327 FEAR OF FALLING AND FOOT PAIN, IMPAIRMENT AND DISABILITY IN RHEUMATOID ARTHRITIS}

J. Bahha, B. Amine, M. Erraoui, Y. Boujenane, S. Fellous, I. El Binoune, R. Bahiri. Rheumatology, Mohammed V University, Faculty of Medicine and Pharmacy of Rabat, El Ayachi Hospital, sale, Morocco

Background: Fear of falling, foot pain and functional disability are commonly reported in rheumatoid arthritis. Moreover, the relationship between the fear of falling and foot pain, impairment and disability has rarely been studied.

Objectives: To evaluate the relationship between fear of falling and foot pain, impairment and disability in patients with established RA.

Methods: A cross-sectional study that included patients with rheumatoid arthritis. We collected the following data: age, sex, duration of disease, foot pain assessed by the Visual Analogue Scale (VAS), Disease activity assessed by DAS 28, HAQ disability index (HAQ-DI). Fear of falling was assessed by Falls Efficacy Scale-International (FES-I) which consists of 16 different activities, scored using a four point scale $(1=$ not at all concerned, $2=$ somewhat concerned, $3=$ fairly concerned and $4=$ very concerned). The summed scores for the 16 activities for each participant were calculated. Scores of $\geq 23$ indicated a significant fear of falling. Foot disability and impairment were measured using the Leeds Foot Impact Scale (LFIS), Foot disability was represented by the total score (LFIST; range 0 to 51) of the LFIS and foot impairment by the first subscale (LFISIF; range 0 to 21). Correlations were used to assess the relationship between fear of falling and foot pain, impairment and disability.

Results: Thirty-three patients were included. The mean age was $49.3 \pm 10.5$ years with female predominance $(n=29(87.9 \%))$. The mean disease duration was $9.9 \pm 7.5$ years. The mean HAQ-DI was $1.3 \pm 0.8$. The mean DAS28 score was $5.5 \pm 1.3$ and the mean EVA foot pain was $5.5 \pm 2.4$. The mean FES-I score was $37.4 \pm 15.1$ and $69.7 \%(n=23)$ of patients had a significant fear of falling. Positive correlations were found between fear of falling and foot impairment $(r=0.66$; $p<0.0001)$ and disability $(r=0.80 ; p<0.0001)$. No correlation was found between fear of falling and foot pain $(r=0.29, p=0.07)$.

Conclusions: The results of this study have demonstrated the importance of the relationship between fear of falling and foot impairment and disability.

Disclosure of Interest: None declared

DOI: 10.1136/annrheumdis-2017-eular.5912

\section{AB0328 RHEUMATOID ARTHRITIS AND FEAR OF FALLING: THE INFLUENCE OF DISEASE ACTIVITY}

J. Bahha, B. Amine, M. Erraoui, Y. Boujenane, S. Fellous, I. El Binoune, R. Bahiri. Rheumatology, Mohammed V University, Faculty of Medicine and Pharmacy of Rabat, El Ayachi Hospital, sale, Morocco

Objectives: The objective of this study was to evaluate fear of falling in patients with established RA and its relation to disease activity.

Methods: A cross-sectional study that included patients with rheumatoid arthritis.
We collected the following data: age, sex, duration of disease, body mass index (BMI). Fear of falling was evaluated by the Falls Efficacy Scale-International score (FES-I) which consists of 16 different activities, scored using a four point scale $(1=$ not at all concerned, $2=$ somewhat concerned, $3=$ fairly concerned and $4=$ very concerned). The summed scores for the 16 activities for each participant were calculated. Scores of $\geq 23$ indicated a significant fear of falling. Disease activity was measured with swollen and tender joint count (SJC28, TJC28), pain on a visual analogue scale (VAS pain), patient and evaluator global assessment of disease activity (PGA, EGA), HAQ disability index (HAQ-DI), 28-joint DAS (DAS-28) and the clinical and simple disease activity indexes (CDAI, SDAI). Correlations were used to assess the relationship between fear of falling and disease activity.

Results: Thirty-three patients were included. The mean age was $49.3 \pm 10.5$ years with female predominance $(n=29(87.9 \%))$. The mean disease duration was $9.9 \pm 7.5$ years.

The mean FES-I score was $37.4 \pm 15.1$ and $69.7 \%(n=23)$ of patients had significant fear of falling. The mean VAS pain was $5.3 \pm 2.5$, the PGA was $6.2 \pm 2.1$ and the EGA was $5.7 \pm 1.7$. The mean HAQ-DI was $1.3 \pm 0.8$. The mean DAS28 score was $5.5 \pm 1.3$. The mean CDAI was $29.9 \pm 13.6$ and the SDAI was $31.6 \pm 13.7$.

FES-I was significantly correlated with TJC28 $(r=0.52, p=0.02), P G A(r=0,56$, $p=0,01)$, EGA $(r=0,39, p=0,025)$, HAQ-DI $(r=0.70, p=0001)$, DAS28 $(r=0,38$, $p=0.029), \operatorname{CDAl}(r=0.48, p=0.005)$ and SDAI $(r=0.52, p=0.002)$.

Conclusions: This study suggests that fear of falling is frequent in patients with rheumatoid arthritis and demonstrated that fear of falling is significantly correlated with disease activity.

Disclosure of Interest: None declared

DOI: 10.1136/annrheumdis-2017-eular.6029

\section{AB0329 DO ANXIOUS OR DEPRESSIVE RHEUMATOID ARTHRITIS PATIENTS ON BIOTECHNOLOGIC THERAPY HAVE WORSE DISEASE ACTIVITY, FUNCTION AND QUALITY OF LIFE?}

J. Borges ${ }^{1}$, N. Madeira ${ }^{1}$, A. Cardoso ${ }^{2}$, L. Cunha-Miranda ${ }^{1}$, F. Barcelos ${ }^{1}$,

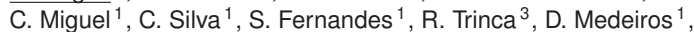

R. Campanilho-Marques ${ }^{1}, H$. Santos ${ }^{1}$, R. Leitão ${ }^{1}$, A. Faustino ${ }^{1}$.

${ }^{1}$ Rheumatology; ${ }^{2}$ Nutrition; ${ }^{3}$ Nursing, Instituto Portugues de Reumatologia, Lisboa, Portugal

Background: Depression, anxiety and fatigue are common symptoms in rheumatoid arthritis (RA) patients, and seem to influence disease activity, pain, quality of life $(\mathrm{QoL})$ and treatment response.

Objectives: To assess disease activity, function and QoL in RA patients with symptoms of anxiety/depression.

Methods: Observational, cross-sectional study including RA patients on bDMARD followed at our centre, registered at Reuma.pt with $\geq 1$ evaluation from 2015/11 to $2016 / 07$. Clinical data including DAS28, CDAI, SDAI, TJC, SJC, patients' and physicians' pain/global assessments (VAS), ESR, CRP, HAQ, EQ5D, HADS score (anxiety and depression domains, cutoff $\geq 8$ ) and FACIT-F were collected. Data were analyzed using Mann-Whitney, Qui-Squared and Spearman correlation, $\mathrm{p}<0.05$.

Results: 182 patients enrolled, $84.6 \%$ female, mean: age at 1 st bDMARD $53.8 \pm 11.1$; time since diagnosis $16.2 \pm 9$.3 years; DAS28 $3.54 \pm 1.3$; CDAI 10.2 \pm 9.6 ; SDAI 11.2 \pm 10.4 ; HAQ 0.97 \pm 0.6 ; HADS-Anxiety 7.13 \pm 4.5 ; HADS-Depression $6.62 \pm 4.54$, FACIT-F 35.1 \pm 9.2 , EQ-5D 0.36 \pm 0.2 .77 (44.5\%) patients scored $\geq 8$ in the HADS-Anxiety domain and $71(41.0 \%)$ scored $>8$ in the HADS-Depression domain. Comparison of depressive vs non-depressive and anxious vs nonanxious groups appears on table 1. There was a correlation of HADS-Anxiety with DAS28 $(r=0.391, p<0.001)$, CDAI $(r=0.441, p<0.001)$, SDAI $(r=0.426, p<0.001)$, HAQ $(r=0.509, p<0.001)$, FACIT-F $(r=-0.669, p<0.001)$ and EQ5D $(r=-0.592$, $p<0.001)$. There was a correlation of HADS-Depression with DAS28 $(r=0.389$, $p<0.001)$, CDAl $(r=0.455, p<0.001)$, SDAl $(r=0.439, p<0.001), H A Q(0.596$, $p<0.001)$, FACIT-F $(r=-0.679, p<0.001)$ and EQ5D $(r=-0.659, p<0.001)$.

Abstract AB0329 - Table 1. Comparison of anxious vs non-anxious and depressive vs non-depressive patients

\begin{tabular}{|c|c|c|c|c|c|c|}
\hline & HADS-A $<8$ & HADS-A $\geq 8$ & $\mathrm{p}$ & HADS-D $<8$ & HADS-D $\geq 8$ & $\mathrm{p}$ \\
\hline $\mathrm{N}$ & 96 & 77 & & 102 & 71 & \\
\hline Gender (M\%) & $18.8 \%$ & $9.1 \%$ & 0.073 & $18.6 \%$ & $8.5 \%$ & 0.061 \\
\hline Age at diagnosis, mean \pm SD (years) & $44.5 \pm 13.2$ & $45.4 \pm 12.7$ & 0.606 & $42.3 \pm 12.7$ & $48.5 \pm 12.5$ & 0.009 \\
\hline Age at 1 st bMARD, mean \pm SD (years) & $53.6 \pm 11.1$ & $54.9 \pm 10.0$ & 0.422 & $52.4 \pm 10.3$ & $56.8 \pm 10.6$ & 0.008 \\
\hline HADS-A, mean $\pm S D$ & & & & $4.99 \pm 3.5$ & $10.2 \pm 4.04$ & $<0.001$ \\
\hline HADS-D, mean $\pm S D$ & $4.1 \pm 3.6$ & $9.6 \pm 3.7$ & $<0.001$ & & & \\
\hline $\mathrm{HAQ}$, mean $\pm \mathrm{SD}$ & $0.75 \pm 0.6$ & $1.26 \pm 0.6$ & $<0.001$ & $0.7 \pm 0.5$ & $1.3 \pm 0.6$ & $<0.001$ \\
\hline DAS28 ESR, mean \pm SD & $3.1 \pm 1.1$ & $4.0 \pm 1.4$ & $<0.001$ & $3.1 \pm 1.0$ & $4.1 \pm 1.5$ & $<0.001$ \\
\hline $28 \mathrm{TJC}$, mean \pm SD & $1.83 \pm 3.3$ & $4.95 \pm 5.8$ & $<0.001$ & $1.92 \pm 3.1$ & $5.08 \pm 6.1$ & $<0.001$ \\
\hline $28 \mathrm{SJC}$, mean $\pm \mathrm{SD}$ & $1.02 \pm 1.7$ & $1.86 \pm 2.7$ & 0.042 & $0.97 \pm 1.5$ & $2.00 \pm 2.9$ & 0.020 \\
\hline $\mathrm{PGA}(\mathrm{VAS})$, mean $\pm \mathrm{SD}$ & $28.46 \pm 23.2$ & $46.3 \pm 24.1$ & $<0.001$ & $28.9 \pm 23.03$ & $47.3 \pm 24.2$ & $<0.001$ \\
\hline Patients' pain assessment (VAS), mean \pm SD & $28.4 \pm 22.5$ & $46.4 \pm 26.2$ & $<0.001$ & $28.8 \pm 22.4$ & $47.3 \pm 26.5$ & $<0.001$ \\
\hline PhGA (VAS), mean \pm SD & $15.9 \pm 13.9$ & $23.8 \pm 20.6$ & 0.022 & $14.4 \pm 12.7$ & $26.5 \pm 20.8$ & $<0.001$ \\
\hline $\mathrm{ESR}(\mathrm{mm} / \mathrm{H})$, mean $\pm \mathrm{SD}$ & $26.42 \pm 19.6$ & $28.43 \pm 21.2$ & 0.513 & $25.3 \pm 18.4$ & $30.2 \pm 22.6$ & 0.190 \\
\hline $\mathrm{CRP}(\mathrm{mg} / \mathrm{L})$, mean $\pm \mathrm{SD}$ & $6.9 \pm 10.9$ & $9.3 \pm 23.5$ & 0.771 & $6.1 \pm 8.9$ & $10.6 \pm 25.3$ & 0.808 \\
\hline $\mathrm{CDAl}$, mean $\pm \mathrm{SD}$ & $7.3 \pm 7.1$ & $13.8 \pm 11.2$ & $<0.001$ & $7.2 \pm 6.4$ & $14.5 \pm 11.7$ & $<0.001$ \\
\hline SDAl, mean \pm SD & $8.2 \pm 7.4$ & $14.96 \pm 12.4$ & $<0.001$ & $7.97 \pm 6.7$ & $15.8 \pm 12.97$ & $<0.001$ \\
\hline FACIT-F, mean \pm SD & $39.8 \pm 7.5$ & $29.3 \pm 7.7$ & $<0.001$ & $39.1 \pm 7.8$ & $29.4 \pm 8.2$ & $<0.001$ \\
\hline EQ5D, mean \pm SD & $0.43 \pm 0.17$ & $0.28 \pm 0.20$ & $<0.001$ & $0.44 \pm 0.17$ & $0.26 \pm 0.19$ & $<0.001$ \\
\hline
\end{tabular}

